\title{
Motor Recovery Mechanisms in Patients with Middle Cerebral Artery Infarct: A Mini-Review
}

\author{
Sung Ho Jang \\ Department of Physical Medicine and Rehabilitation, College of Medicine, Yeungnam University, Taegu, \\ Republic of Korea
}

\section{Key Words}

Stroke $\cdot$ Diffusion tensor imaging $\cdot$ Diffusion tensor tractography $\cdot$ Middle cerebral artery $\cdot$ Motor recovery • Brain plasticity

\begin{abstract}
Previous studies on the mechanisms of motor recovery in patients with middle cerebral artery (MCA) infarct except for the studies on cortical peri-infarct reorganization after primary motor cortex infarct were reviewed. Eight studies were classified and reviewed by the following four motor recovery mechanisms: contribution of premotor cortex, subcortical peri-infarct reorganization, ipsilateral motor pathway, and contribution of aberrant motor pathway. MCA infarct is the most common type among the arterial territory infarcts. In addition, MCA territory is important for motor function because it comprises the corticospinal tract, the corticoreticulospinal tract and the neural tracts which are related with apraxia (superior longitudinal fasciculus and corticofugal fibers from the premotor cortex). In spite of the significance of the MCA territory for motor function, fewer studies have reported on the mechanisms of motor recovery in MCA infarct compared to total number of studies about cerebral infarct. In addition, the majority of these studies have focused on the corticospinal tract. Therefore, the total number of studies on this topic should be increased. We believe that
\end{abstract}

further studies comprising other neural tracts except for the corticospinal tract including the extrapyramidal tracts such as the corticoreticulospinal and neural tracts which are related with apraxia, are necessary.

Copyright $\odot 2012$ S. Karger AG, Basel

\section{Introduction}

Middle cerebral artery (MCA) infarct is the most common type among the cerebral vascular territory infarcts [1]. In addition, patients with MCA infarct are known to become highly dependent for daily activities [1-3]. That seems to be related to the characteristics of the MCA territory for motor function. The MCA territory comprises the corticospinal tract (CST) which is mandatory for fine motor activity of hand, the corticoreticulospinal tract which is involved in postural control and locomotor function, the corticofugal fibers which are responsible for limb-kinetic apraxia, and the anterior portion of superior longitudinal fasciculus which is related with ideomotor apraxia [4-16].

Elucidation of the mechanisms of motor recovery in stroke is important because such information could provide the scientific information for stroke rehabilitation and for prediction of prognosis. Therefore, many studies have tried to clarify the motor recovery mechanisms in

\section{KARGER}

Fax +4161306 1234

E-Mail karger@karger.ch

www.karger.com (c) 2012 S. Karger AG, Basel

0014-3022/12/0684-0234\$38.00/0

Accessible online at:

www.karger.com/ene
Sung Ho Jang, MD

Department of Physical Medicine and Rehabilitation, College of Medicine

Yeungnam University 317-1, Daemyungdong, Namku

Taegu 705-717 (Republic of Korea)

Tel. +82 53620 3269, E-Mail strokerehab @ hanmail.net 
stroke and several recovery mechanisms have been suggested: the ipsilateral motor pathway from the unaffected motor cortex to the affected extremities, perilesional reorganization, recovery of a damaged lateral CST and contribution of the secondary motor area [17-19]. However, as for the patients with MCA infarct, relatively fewer studies have reported on the mechanisms of motor recovery compared to total number of studies about cerebral infarct, consequently, the mechanisms of motor recovery in MCA infarct have not been clearly elucidated so far [20-27].

In the current study, we reviewed previous studies with regard to the mechanisms of recovery in patients with MCA infarct. Relevant studies were identified using the following electronic databases: PubMed and MEDLINE, from 1966 to 2012. The following key words were used: stroke, MCA, cerebral infarct, CST, corticoreticulospinal tract, brain plasticity, rehabilitation, motor recovery, functional recovery, hemiparesis, diffusion tensor imaging (DTI), diffusion tensor tractography (DTT), functional MRI (fMRI) and transcranial magnetic stimulation (TMS). We confined to the pure motor recovery mechanism excluding apraxia-related or intervention-induced motor recovery. In addition, we excluded the studies on cortical peri-infarct reorganization after primary motor cortex infarct because this topic was already reviewed in detail by a previous review paper [28]. Eight studies on the mechanisms of motor recovery in MCA infarct were selected for this review [20-27]. These studies were classified according to the following four motor recovery mechanisms: the contribution of premotor cortex (PMC), subcortical peri-infarct reorganization, ipsilateral motor pathway and contribution of aberrant motor pathway.

\section{Contribution of the Premotor Cortex}

The PMC is an important area in terms of motor recovery for the following reasons. First, the corticoreticulospinal tract, which innervates the proximal muscles of extremities and axial muscles as one of the extrapyramidal motor pathways, originates mainly from the PMC [7, $9,12,13,29]$. Second, the CST originates from a variety of areas in the cerebral cortex including the PMC $[4,16$, $30,31]$. It was reported in monkeys that $31 \%$ of the descending fibers in the pyramid come from the primary motor cortex, $29 \%$ from the PMC, and $40 \%$ from the parietal lobe [31]. Finally, one of the important roles of the PMC is planning of motor execution [32-34].

Motor Recovery Mechanisms in MCA Infarct
Two studies have reported on the contribution of the PMC for motor recovery in patients with MCA infarct $[25,26]$. In 1998, Seitz et al. [26] recruited 7 patients with MCA infarct who showed marked recovery of hand function after severe hemiparesis. They found that the bilateral PMC was activated during affected finger movements without the activation of the primary sensorimotor cortex of either hemisphere by positron emission tomography. The motor-evoked potentials in the hand and leg muscles contralateral to the infarcts were normal. Therefore, they suggested that motor recovery in these patients appeared to rely on activation of the PMC of both cerebral hemispheres. Subsequently, Miyai et al. [25] compared the characteristics of motor recovery according to the presence of PMC lesions in 31 patients with MCA infarct. They found that patients with intact PMC showed better recovery in terms of mobility and motor function of the hip than patients with PMC lesion. As a result, they concluded that the presence of PMC involvement could affect the recovery of locomotor function in patients with MCA infarct.

\section{Subcortical Peri-Infarct Reorganization}

Peri-infarct reorganization indicates the transfer of motor function into adjacent areas of an infarct. There have been many studies on peri-infarct reorganization of affected motor function in stroke patients [28, 35-40]. However, the majority of these studies have been focused on peri-infarct reorganization at the cortical level $[28,35$, $36,38,40]$. The recent development of DTI allows analysis of motor pathways at the subcortical level and several studies have reported on peri-infarct reorganization at the subcortical level $[20-22,35,39]$. To the best of our knowledge, three studies have reported on peri-infarct reorganization in the subcortical white matter after MCA infarct [20-22].

In 2009, Jang [22] reported on a patient whose leg motor function appeared to be reorganized into the region of the wall of the lateral ventricle following a MCA infarct, using DTT, fMRI and TMS. The patient presented with complete paralysis of the right extremities at the onset of left MCA infarct, and recovered slowly, to the point of being able to extend the affected knee against resistance by 9 months without recovery of the affected hand. The affected CST descended through the medial corona radiata at or around the wall of the lateral ventricle on DTT. TMS (the motor-evoked potential obtained from the affected leg muscle showed the charac- 
Table 1. Previous studies on mechanisms of motor recovery in patients with MCA infarct

\begin{tabular}{|c|c|c|c|c|}
\hline Recovery mechanism & Study group & $\begin{array}{l}\text { Publication } \\
\text { year }\end{array}$ & $\begin{array}{l}\text { Patients } \\
\mathrm{n}\end{array}$ & Evaluation method \\
\hline \multirow[t]{2}{*}{ Contribution of premotor cortex } & Seitz et al. [26] & 1998 & 7 & PET, TMS \\
\hline & Miyai et al. [25] & 1999 & 31 & MRI \\
\hline \multirow[t]{2}{*}{ Subcortical peri-infarct reorganization } & Jang SH [22] & 2009 & 1 & DTT, fMRI, TMS \\
\hline & Hong et al. [20] & 2010 & 1 & DTT, fMRI, TMS \\
\hline & Yeo and Jang [27] & 2012 & 1 & DTT, fMRI \\
\hline Aberrant motor pathway & Lindenberg et al. [24] & 2010 & 35 & DTT \\
\hline
\end{tabular}

teristics of the CST in terms of latency $(34.0 \mathrm{~ms})$ and amplitude $(2.0 \mathrm{mV})$ ) and fMRI (the contralateral primary sensorimotor cortex was activated during the affected knee movements) for motor function of the affected leg showed results compatible with those for the lateral CST. Findings from this study indicated the importance of the subventricular zone, which is known to have potential for neurogenesis, even in the mature brain [41]. Subsequently, Hong and Jang [20] reported on a patient who recovered via the spared anterior choroidal artery territory following a MCA infarct, using DTT, TMS and fMRI. The patient presented with complete paralysis of the left extremities at the onset of MCA infarct. Motor function of the affected extremities recovered to a nearly normal state 6 months after onset. The 2-week DTT for the CST showed interruption below the infarct. However, the affected CST on 6-month DTT descended through the spared periventricular area (anterior choroidal artery territory) along the known CST pathway. TMS (the motor-evoked potential obtained from the affected hand muscle showed the characteristics of the CST in terms of latency (23.4 ms) and amplitude $(1.3 \mathrm{mV})$ ) and fMRI (the contralateral primary sensorimotor cortex was activated during the affected hand movements) revealed that the motor pathway for the affected hand was compatible with the lateral CST. As a result, they concluded that motor function of the affected hand seemed to be recovered by the CST that passed through the spared anterior choroidal artery territory following a MCA infarct. Recently, Hong and Jang [21] demonstrated perilesional reorganization in a patient with a MCA infarct, using DTT ana- lyzed using fMRI activation results. The patient presented with complete paralysis of the right extremities at onset of the left MCA infarct. His hand function recovery was slow and he gained the ability to extend the affected fingers against gravity 3 years after stroke onset. The CST of the affected hemisphere originated from the primary motor cortex and descended along the anterior portion of the infarcted area at the centrum semiovale and spared the periventricular area at the middle corona radiata. At the centrum semiovale and corona radiata of the affected hemisphere, the affected CST was located anteriorly, compared with the CST of the unaffected hemisphere. Therefore, they suggested that the motor function of the affected hand seemed to have been reorganized into anterior areas of the infarcted centrum semiovale and corona radiata.

\section{Ipsilateral Motor Pathway}

The ipsilateral motor pathway is the neural pathway from a motor cortex to the same extremities. The ipsilateral motor pathway is a normal motor control pathway and has been accepted as one of the recovery mechanisms of stroke [42-44]. Among the mechanisms of motor recovery after stroke, the ipsilateral motor pathway from the unaffected motor cortex to the affected extremities has been the most actively researched [43]. It is important because it is related to poor motor outcome and can change with time or manipulated by various rehabilitative interventions [42, 43, 45-49]. However, only 
a few studies have been conducted in MCA infarct [23, 27].

In 2001, Kato et al. [23] reported on a patient who showed ipsilateral motor pathway following a MCA infarct. The left hemiparesis of the patient recovered excellently following a right MCA infarct and fMRI was performed at 6 years after onset. During right (unaffected) hand grasping, activation was seen in the left (unaffected) sensorimotor cortex and supplementary motor areas. During the affected (left) hand grasping, activation was seen in the unaffected (left: ipsilateral) sensorimotor cortex, right parietal cortex and bilateral supplementary motor areas. Near infrared spectroscopy and TMS showed similar results. Therefore, the findings of the three techniques indicated that the recovery of the left hemiparesis of this patient had been recovered by motor cortical area reorganization including the ipsilateral motor cortex. Recently, Yeo and Jang [27] reported on a patient with a MCA infarct who showed an ipsilateral motor pathway without the contralateral motor pathway on fMRI and DTT. The patient revealed severe left hemiplegia following an infarct in the right MCA. During a 3-month period after onset, motor function of the affected (left) hand had recovered slowly to the extent that the patient was able to overcome gravity. fMRI showed that only the unaffected primary sensorimotor cortex was activated by movements of the unaffected hand or of the affected hand. On DTT, the CST in the unaffected hemisphere originated from the primary sensorimotor cortex and descended through the known CST pathway. By contrast, the CST in the affected hemisphere revealed an interruption with wallerian degeneration to the upper medulla. They concluded that motor function of the affected hand appeared to have been reorganized to the ipsilateral motor pathway from the unaffected motor cortex to the affected hand.

\section{Contribution of Aberrant Motor Pathway}

In 2010, Lindenberg et al. [24] suggested that the alternate motor pathway at the brainstem could contribute to the motor recovery in patients with MCA infarct. They recruited 35 chronic patients with varying degrees of recovery and classified them into three groups using DTT findings for motor tracts. The motor functions of the affected side were better in the following order: patients who had both pyramidal tract and alternate motor fibers in the posterior pons, patients who had alternate motor fibers in the posterior pons without the pyramidal tract

Motor Recovery Mechanisms in MCA Infarct involvement, and patients who did not have any fibers of the pyramidal tract or alternate motor fibers in the posterior pons. These results seemed to suggest that the alternate motor fibers in the posterior pons could contribute to motor recovery in patients with MCA infarct. Although they did not declare the exact pathway of the alternate motor fibers in their study, the alternate motor fibers appeared to be the aberrant pyramidal tract which separates from the original pyramidal tract at the level of the midbrain and the pons and descends through the medial lemniscus [50-53]. It is well known that the pyramidal tract has collateral pathways [54, 55]. The aberrant pyramidal tract is a collateral pathway of the pyramidal tract and existence of the aberrant pyramidal tract has been demonstrated by various methods, including pathological, electrophysiological and radiological $[50-53,56]$. In addition, recently, the aberrant pyramidal tract has been suggested as a motor recovery mechanism in patients with an infarct in the pons, midbrain and corona radiata [57-59].

\section{Conclusion}

In the current study, 8 studies were classified by the following motor recovery mechanisms: contribution of the premotor cortex (2 studies), subcortical peri-infarct reorganization (3 studies), ipsilateral motor pathway (2 studies) and contribution of the aberrant motor pathway (1 study) [20-27]. The MCA territory is an important area for motor function because it is comprised of the CST, the corticoreticulospinal tract and neural tracts which are related with apraxia [4-16]. In addition, the MCA occupies the largest area among the cerebral artery territories and has many branches. This means that MCA infarct can cause various and serious motor dysfunction, consequently, there is a possibility that various mechanisms of motor recovery can occur after MCA infarct. Therefore, for the best outcome of the patients with MCA infarct, it seems that clinicians should understand the possible motor recovery mechanism which is most beneficial for a patient and facilitate that recovery mechanism through the rehabilitative interventions irrespective of motor outcome of each motor recovery mechanism. In spite of the characteristics of MCA territory for motor function, fewer studies have reported on the motor recovery mechanisms in MCA compared to total number of studies about cerebral infarct. In addition, the majority of these studies have focused on the CST. We believe that the total number of studies on this 
topic should be increased. Furthermore, further studies comprising other neural tracts including the extrapyramidal tracts such as the corticoreticulospinal tract and the neural tracts which are related with apraxia, are necessary.

\section{Acknowledgement}

This work was supported by the DGIST R\&D Program of the Ministry of Education, Science and Technology of Korea (11-IT01).

\section{References}

$>1$ Ng YS, Stein J, Ning M, Black-Schaffer RM: 16 York DH: Review of descending motor pathComparison of clinical characteristics and functional outcomes of ischemic stroke in different vascular territories. Stroke 2007;38: 2309-2314.

-2 Balaban B, Tok F, Yavuz F, Yasar E, Alaca R: Early rehabilitation outcome in patients with middle cerebral artery stroke. Neurosci Lett 2011;498:204-207.

-3 Mills VM, DiGenio M: Functional differences in patients with left or right cerebrovascular accidents. Phys Ther 1983;63:481-488.

4 Davidoff RA: The pyramidal tract. Neurology 1990;40:332-339.

5 Gross RG, Grossman M: Update on apraxia. Curr Neurol Neurosci Rep 2008;8:490-496.

6 Hong JH, Jang SH: Limb apraxia in a patient with cerebral infarct: diffusion tensor tractography study. NeuroRehabilitation 2012; $30: 255-259$.

7 Jang SH: The recovery of walking in stroke patients: a review. Int J Rehabil Res 2010;33: 285-289.

${ }_{8}$ Jang SH: The role of the corticospinal tract in motor recovery in patients with a stroke: a review. NeuroRehabilitation 2009;24:285-290.

$\checkmark 9$ Kably B, Drew T: Corticoreticular pathways in the cat. II. Discharge activity of neurons in area 4 during voluntary gait modifications. J Neurophysiol 1998;80:406-424.

10 Kwon HG, Jang SH: Delayed recovery of gait function in a patient with intracerebral hemorrhage. J Rehabil Med 2012;44:378-380.

11 Leiguarda RC, Marsden CD: Limb apraxias: higher-order disorders of sensorimotor integration. Brain 2000;123:860-879.

12 Matsuyama K, Mori F, Nakajima K, Drew T, Aoki M, Mori S: Locomotor role of the corticoreticular-reticulospinal-spinal interneuronal system. Prog Brain Res 2004;143:239249.

13 Mendoza JE, Foundas AL: Clinical Neuroanatomy: A Neurobehavioral Approach. New York, Springer, 2007.

- 14 Newton JM, Ward NS, Parker GJ, Deichmann R, Alexander DC, Friston KJ, Frackowiak RS: Non-invasive mapping of corticofugal fibres from multiple motor areas relevance to stroke recovery. Brain 2006;129: 1844-1858.

$\checkmark 15$ Schmahmann JD, Smith EE, Eichler FS, Filley CM: Cerebral white matter: neuroanatomy, clinical neurology, and neurobehavioral correlates. Ann NY Acad Sci 2008;1142:266-309. ways involved with transcranial stimulation. Neurosurgery 1987;20:70-73.

17 Binkofski F, Seitz RJ, Arnold S, Classen J, Benecke R, Freund HJ: Thalamic metabolism and corticospinal tract integrity determine motor recovery in stroke. Ann Neurol 1996; 39:460-470.

18 Calautti C, Baron JC: Functional neuroimaging studies of motor recovery after stroke in adults: a review. Stroke 2003;34:15531566.

19 Jang SH: A review of diffusion tensor imaging studies on motor recovery mechanisms in stroke patients. NeuroRehabilitation 2011; 28:345-352.

20 Hong JH, Jang SH: Motor recovery by anterior choroidal artery territory in a patient with middle cerebral artery infarct. Neural Regen Res 2010;5:1357-1360 (www.nrronline.org).

21 Hong JH, Jang SH: Peri-infarct reorganization at the centrum semiovale and corona radiata: a diffusion tensor tractography and functional MRI study. Neural Regen Res 2011;6:826-829 (www.nrronline.org).

22 Jang SH: Medial reorganization of motor function in corona radiata following middle cerebral artery infarction: a case report. Neural Regen Res 2009;4:668-671 (www. nrronline.org).

23 Kato H, Izumiyama M, Shiga Y, Saito N, Koizumi H, Takahashi A, Itoyama Y: Hand motor cortical area reorganization following cerebral infarction evaluated with functional MRI, near infrared spectroscopic imaging, and transcranial magnetic stimulation. No To Shinkei 2001;53:869-874.

24 Lindenberg R, Renga V, Zhu LL, Betzler F, Alsop D, Schlaug G: Structural integrity of corticospinal motor fibers predicts motor impairment in chronic stroke. Neurology 2010;74:280-287.

25 Miyai I, Suzuki T, Kang J, Kubota K, Volpe BT: Middle cerebral artery stroke that includes the premotor cortex reduces mobility outcome. Stroke 1999;30:1380-1383.

26 Seitz RJ, Hoflich P, Binkofski F, Tellmann L, Herzog H, Freund HJ: Role of the premotor cortex in recovery from middle cerebral artery infarction. Arch Neurol 1998;55:10811088.
27 Yeo SS, Jang SH: Ipsilateral motor pathway without contralateral motor pathway in a stroke patient. NeuroRehabilitation 2012;30: 303-306.

28 Jang SH: Perilesional reorganization of motor function in stroke patients. Neural Regen Res 2010;5:1668-1672 (www.nrronline.org).

29 Kably B, Drew T: Corticoreticular pathways in the cat. I. Projection patterns and collaterization. J Neurophysiol 1998;80:389-405.

30 Jane JA, Yashon D, DeMyer W, Bucy PC: The contribution of the precentral gyrus to the pyramidal tract of man. J Neurosurg 1967; 26:244-248.

31 Russell JR, Demyer W: The quantitative corticoid origin of pyramidal axons of macaca rhesus. With some remarks on the slow rate of axolysis. Neurology 1961;11:96-108.

32 Donoghue JP, Sanes JN: Motor areas of the cerebral cortex. J Clin Neurophysiol 1994;11: 382-396.

-33 Freund HJ: Premotor area and preparation of movement. Rev Neurol (Paris) 1990;146: 543-547.

34 Passingham RE: Two cortical systems for directing movement. Ciba Found Symp 1987; 132:151-164.

35 Ahn YH, You SH, Randolph M, Kim SH, Ahn SH, Byun WM, Yang DS, Jang SH: Periinfarct reorganization of motor function in patients with pontine infarct. NeuroRehabilitation 2006;21:233-237.

- 36 Cramer SC, Moore CI, Finklestein SP, Rosen BR: A pilot study of somatotopic mapping after cortical infarct. Stroke 2000;31:668-671.

37 Jaillard A, Martin CD, Garambois K, Lebas JF, Hommel M: Vicarious function within the human primary motor cortex? A longitudinal fMRI stroke study. Brain 2005;128:1122-1138.

38 Jang SH, Ahn SH, Lee J, Cho YW, Son SM: Cortical reorganization of sensorimotor function in a patient with cortical infarct. NeuroRehabilitation 2010;26:163-166.

39 Kwon YH, Lee CH, Ahn SH, Lee MY, Yang DS, Byun WM, Park JW, Jang SH: Motor recovery via the peri-infarct area in patients with corona radiata infarct. NeuroRehabilitation 2007;22:105-108.

40 Rossini PM, Caltagirone C, Castriota-Scanderbeg A, Cicinelli P, Del Gratta C, Demartin M, Pizzella V, Traversa R, Romani GL: Hand motor cortical area reorganization in stroke: a study with fMRI, MEG and TCS maps. Neuroreport 1998;9:2141-2146. 
41 Ohab JJ, Carmichael ST: Poststroke neurogenesis: emerging principles of migration and localization of immature neurons. Neuroscientist 2008;14:369-380.

-42 Chen R, Cohen LG, Hallett M: Role of the ipsilateral motor cortex in voluntary movement. Can J Neurol Sci 1997;24:284-291.

43 Jang SH: A review of the ipsilateral motor pathway as a recovery mechanism in patients with stroke. NeuroRehabilitation 2009;24: 315-320.

44 Kim SG, Ashe J, Hendrich K, Ellermann JM, Merkle H, Ugurbil K, Georgopoulos AP: Functional magnetic resonance imaging of motor cortex: hemispheric asymmetry and handedness. Science 1993;261:615-617.

45 Chen R, Gerloff C, Hallett M, Cohen LG: Involvement of the ipsilateral motor cortex in finger movements of different complexities. Ann Neurol 1997;41:247-254.

46 Ehrsson HH, Fagergren A, Jonsson T, Westling G, Johansson RS, Forssberg $\mathrm{H}$ : Cortical activity in precision- versus powergrip tasks: an fMRI study. J Neurophysiol 2000;83:528-536.
47 Marshall RS, Perera GM, Lazar RM, Krakauer JW, Constantine RC, DeLaPaz RL: Evolution of cortical activation during recovery from corticospinal tract infarction. Stroke 2000;31:656-661.

48 Takeuchi N, Chuma T, Matsuo Y, Watanabe I, Ikoma K: Repetitive transcranial magnetic stimulation of contralesional primary motor cortex improves hand function after stroke. Stroke 2005;36:2681-2686.

49 Traversa R, Cicinelli P, Bassi A, Rossini PM, Bernardi G: Mapping of motor cortical reorganization after stroke. A brain stimulation study with focal magnetic pulses. Stroke 1997;28:110-117.

-50 Hong JH, Son SM, Byun WM, Jang HW, Ahn $\mathrm{SH}$, Jang SH: Aberrant pyramidal tract in medial lemniscus of brainstem in the human brain. Neuroreport 2009;20:695-697.

-51 Kwon HG, Son SM, Chang MC, Kim S, Kwon YH, Jang SH: Characteristics of the aberrant pyramidal tract in comparison with the pyramidal tract in the human brain. BMC Neurosci 2011;12:108.

52 Yamamoto T: Aberrant pyramidal tract: a clinicopathological review. Neurol Med (Tokyo) 1995;43:306-312.

53 Yamashita M, Yamamoto T: Aberrant pyramidal tract in the medial lemniscus of the human brainstem: normal distribution and pathological changes. Eur Neurol 2001;45: $75-82$.
54 Nathan PW, Smith MC: Long descending tracts in man. I. Review of present knowledge. Brain 1955;78:248-303.

55 Nyberg-Hansen R, Rinvik E: Some comments on the pyramidal tract, with special reference to its individual variations in man. Acta Neurol Scand 1963;39:1-30.

56 Yamamoto T, Yamasaki M, Imai T: Retrograde pyramidal tract degeneration in a patient with cervical haematomyelia. J Neurol Neurosurg Psychiatry 1989;52:382-386.

57 Hong JH, Jang SH: Aberrant pyramidal tract in a patient with corona radiata infarct: a diffusion tensor tractography study. Neural Regen Res 2011;6:1027-1030 (www.nrronline. org).

58 Jang SH: Aberrant pyramidal tract in the medial lemniscus of the brainstem in a patient with a pontine infarct: diffusion tensor tractography study. J Neurol Neurosurg Psychiatry 2009;80:243-244.

59 Yeo SS, Jang SH: Motor recovery via aberrant pyramidal tract in a patient with a cerebral peduncle infarct. Neural Regen Res 2011;6: 1023-1026 (www.nrronline.org). 